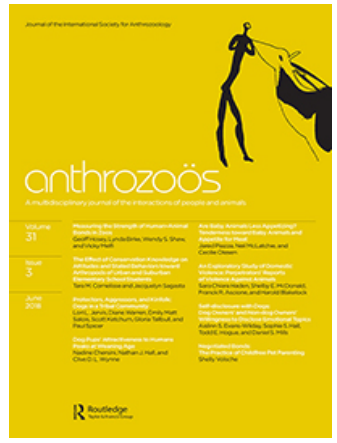

Anthrozoös

A multidisciplinary journal of the interactions of people and animals

ISSN: 0892-7936 (Print) 1753-0377 (Online) Journal homepage: http://www.tandfonline.com/loi/rfan20

\title{
Self-disclosure with Dogs: Dog Owners' and Non- dog Owners' Willingness to Disclose Emotional Topics
}

\author{
Aislinn S. Evans-Wilday, Sophie S. Hall, Todd E. Hogue \& Daniel S. Mills
}

To cite this article: Aislinn S. Evans-Wilday, Sophie S. Hall, Todd E. Hogue \& Daniel S. Mills (2018) Self-disclosure with Dogs: Dog Owners' and Non-dog Owners' Willingness to Disclose Emotional Topics, Anthrozoös, 31:3, 353-366, DOI: 10.1080/08927936.2018.1455467

To link to this article: https://doi.org/10.1080/08927936.2018.1455467

曲 Published online: 03 May 2018.

Submit your article to this journal $\pi$

Q View related articles $\sqsubset$

View Crossmark data $\complement$ 
Address for correspondence:

Sophie S. Hall,

School of Life Sciences, University of Lincoln, Lincoln, LN6 7DL, UK. E-mail: shall@lincoln.ac.uk

\title{
Self-disclosure with Dogs: Dog Owners' and Non-dog Owners' Willingness to Disclose Emotional Topics
}

\author{
Aislinn S. Evans-Wilday, Sophie S. Hall, Todd E. Hogue, \\ and Daniel S. Mills \\ School of Life Sciences, University of Lincoln, Lincoln, UK
}

\begin{abstract}
Many owners talk to their pets about a wide range of issues, but there is very little research that has considered the content of this, or its impact on owner wellbeing. Verbal disclosure brings a range of potential health benefits, yet a number of factors may prevent individuals from confiding in their partners or friends (confidants). As such, in some circumstances, dogs may provide a more favorable alternative focus for disclosure. In a survey, we assessed dog owners' $(n=286)$ and non-dog owners' ( $n=64$ ) self-reported willingness to talk to their dog (dog owners only), their partner and their confidant. We used the Emotional Self Disclosure Scale (ESDS) for non-dog owners, and an adapted version of this for dog owners: Emotional Self Disclosure Scale-Dog Owners (ESDS-DO). Both dog owners and non-dog owners demonstrated a greater willingness to disclose to their partner than a confidant. For dog owners, their dog appeared to play a similar role as their partner, with greater willingness to talk to their dog about depression, jealousy, anxiety, calmness, apathy, and fear-related emotions, compared with a confidant. When talking about jealousy and apathy, dog owners reported greater willingness to talk to their dog than their partner or a confidant, but between-group comparisons (dog owner vs non-dog owner) revealed that dog owners and non-dog owners did not significantly differ in their willingness to talk to their partner or confidant, suggesting human relationships were not negatively affected by confiding to the dog. Participant age and length of relationship with their partner did not affect disclosure patterns for dog owners or non-dog owners. Males and females showed different willingness to disclose to confidants, but not to dogs. The results have implications for considering the value of dogs for human psychological health.
\end{abstract}

Keywords: dogs, human-animal interaction, relationship types, self-disclosure 


\section{Background}

Despite few areas having received as much cross-disciplinary interest as the topic of disclosure (revealing information about oneself to another) (Derlaga \& Berg, 2013), there is little research investigating disclosure in the field of human-animal interactions.

There are many recorded health benefits of disclosure to others, such as reduced stress, depression, and physical illness, and improved sleep and closeness in relationships (Kane, Slatcher, Reynolds, Repetti, \& Robles, 2014; Koing, Eonta, Dyal, \& Vrana, 2014; Richardson \& Rice, 2015; Schrodt \& Afifi, 2016). Indeed, the importance of disclosure is emphasized in a number of clinical and counselling therapies (Derlaga \& Berg, 2013). Research suggests that age and sex differences may affect self-disclosures. Females have been shown to disclose more than males during face-to-face interactions with confidants (Dindia \& Allen, 1992; Horne \& Johnson, 2017), but these sex differences are not so apparent with online (social media) disclosures (Hollenbaugh \& Ferris, 2014). Levels of self-disclosure are thought to decline with age in both face-to-face (Knapp, Ellis, \& Williams, 1980; Sinha, 1972) and social media (Ma \& Leung, 2006; Valkenburg \& Peter, 2007) interactions.

Disclosure to a friend or family member may not always be possible or beneficial; for instance due to the timing or the situation (Greene, Derlega, \& Mathews, 2006), the moods of those involved (Forgas, 2011), or the topic of the disclosure (Tokić \& Pećnik, 2011). In contrast, pets may offer a less judgmental and more readily available source with which to disclose. The premise behind a number of structured animal-assisted interventions (AAl) is that the presence of a friendly pet (typically a dog) promotes disclosure within a therapy session (Cirulli, Borgi, Berry, Francia, \& Alleva, 2011; Geist, 2011; Schneider \& Harley, 2006). Individuals may experience similar benefits within the home, by disclosing to family pets. Indeed, there is increasing recognition that untrained pet dogs can bring some benefits similar to those of trained therapy dogs to high-stress families (e.g., Hall, Wright, Hames, PAWS Team, \& Mills, 2016; Wright et al., 2015). Furthermore, there is evidence to suggest that the presence of a pet improves feelings of support (Bryan et al., 2014) and reduces physiological reactions (e.g., heart rate, blood pressure) to stress better than the presence of a friend or a spouse (Allen, Blascovich, Tomaka, \& Kelsey, 1991; Allen, Blascovich, \& Mendes, 2002; Allen, 2003). As such, talking to a pet may provide a more effective way to alleviate stress than talking to a human confidant.

In spite of growing interest in the value of pets to human health (e.g., Matchock, 2015; McNicholas et al., 2005; O'Haire, 2010; Mills \& Hall, 2014), the role of disclosure in pet ownership appears to have been largely overlooked. Given the potential importance of disclosure, this topic deserves serious scientific attention, especially among dog owners, who reportedly spend more time talking to their pet than owners of other species (Siegel, 1990) and perceive their dog as a source of comfort (Knight \& Edwards, 2008). The limited amount of research in this area has primarily focused on who is more likely to disclose to their pet. Evidence suggests that dog owners are more likely to turn to their dog during times of emotional distress than their immediate genetically-related family (e.g., mother) or close friends, but less likely to turn to their dog than their romantic partner (Kurdek, 2009). Factors such as being male, widowed, strongly involved in the dog's care, and being uncomfortable with self-discourse are associated with a greater likelihood of self-disclosure to the dog (Kurdek, 2009). In contrast, a recent study with children showed that girls are more likely than boys to report self-disclosure to their pets (Cassels, White, Gee, \& Hughes, 2017). These conflicting results may be due to differences between adult and child populations, but it is also 
possible that the broad issue of "disclosure" is too vague a concept; instead, research needs to focus on specific elements within it.

In this study, we explored self-reported willingness to disclose emotional topics to a partner, a confidant (i.e., close friend) and a pet dog (dog owners only) in dog owners and non-dog owners. We were also interested in assessing whether factors such as participant age, sex, length of relationship with dog/partner, and dog sex affected disclosure patterns.

\section{Methods Ethics}

The study procedure (for all the studies reported in this paper) received ethical approval from the University of Lincoln's College of Science Ethics Committee. Respondents provided consent via the first page of an electronic survey, where they had to indicate agreement before proceeding, or choose to exit the survey. The consent form contained statements and directions regarding the nature of the study, the anonymity of the data, withdrawal, how the data would be stored, and intended use of the data.

\section{Participants}

In total, 595 participants responded to the survey. Because only a small number of homosexual participants responded $(n=26)$, we chose to analyze data from heterosexual participants only. From the remaining 569 participants, 206 were excluded due to the amount of missing data (mainly exiting the survey after consent, before completion of demographic information). The majority of respondents resided in either Europe or North America, therefore we excluded the 13 participants who were outside of these regions. The remaining sample consisted of 286 dog owners and 64 non-dog owners. Demographic information is reported in Table 1.

\section{Materials}

Self-disclosure with Dogs: We adapted the Emotional Self-Disclosure Scale (ESDS, Snell, Miller, \& Belk, 1988). This well-used scale asks participants to rate on a 5-point Likert scale ( 1 = Not at all willing; 5 = Totally willing) how willing they would be to discuss 40 emotional items with different recipients; typically a female friend, a male friend, and their spouse/partner. The ESDS was chosen for its excellent reliability and versatility (Snell et al., 1988). The scale has been adapted for use with different recipients, such as with therapists (Rogers, Griffin, Wykle, \& Fitzpatrick, 2009), making it ideal for adaptation for exploring disclosure with dogs.

The 40 items comprise eight subscales (1) Depression, (2) Happiness, (3) Jealousy (4) Anxiety, (5) Anger, (6) Calmness, (7) Apathy, and (8) Fear, with five items per subscale (items are totaled within each subscale, giving a maximum subscale score of 25). The following alteration was made to the original scale: Participants were asked how willing they would be to talk to their partner, dog, or confidant (close friend) about a topic, so that "talk ... about" replaced the original word "discuss", as dogs cannot reciprocate in a way implied by the term "discuss", but "talk about" maintains the essence of disclosure. Example items include "How willing are you to talk to the following individuals about times when you have felt fearful?" and "How willing are you to talk to the following individuals about times when you have felt discouraged?" Underneath the question, the Likert scale was presented adjacent to the list of individuals (dog, partner, confidant). The order of presentation of the recipient of the disclosure (dog, partner, confidant) was randomized via a computer generated system. Non-dog owners were not presented with the "dog" option and therefore had fewer items to complete. The version of the 
Table 1. Demographic details of the respondents.

\begin{tabular}{|c|c|c|c|}
\hline Demographic & Categories & $\begin{array}{l}\text { Dog Owners } \\
\quad(n=286)\end{array}$ & $\begin{array}{l}\text { Non-dog Owners } \\
\quad(n=64)\end{array}$ \\
\hline \multirow[t]{2}{*}{ Sex } & Male & $39(13.6 \%)$ & $10(15.6 \%)$ \\
\hline & Female & 247 (86.4\%) & 54 (84.4\%) \\
\hline \multirow[t]{2}{*}{ Country of Residence } & Europe & $221(77 \%)$ & $57(89.1 \%)$ \\
\hline & North America & $67(23 \%)$ & 7 (10.9\%) \\
\hline \multirow[t]{7}{*}{ Age } & 18-25 years & 39 (13.6\%) & $16(25 \%)$ \\
\hline & 26-35 years & 81 (28.3\%) & 22 (34.4\%) \\
\hline & 36-45 years & 60 (21\%) & 7 (10.9\%) \\
\hline & 46-55 years & $70(24.5 \%)$ & $8(12.5 \%)$ \\
\hline & 56-65 years & 29 (10.1\%) & $9(14.1 \%)$ \\
\hline & $66-75$ years & $6(2.1 \%)$ & $2(3.1 \%)$ \\
\hline & $75+$ years & $1(0.3 \%)$ & $0(0 \%)$ \\
\hline \multirow[t]{12}{*}{ Length of Relationship with Partner } & $<1$ year & $15(5.2 \%)$ & $2(3.1 \%)$ \\
\hline & $1-5$ years & $58(20.3 \%)$ & 35 (54.7\%) \\
\hline & $6-10$ years & 67 (23.4\%) & $10(15.6 \%)$ \\
\hline & $11-15$ years & 47 (16.4\%) & 7 (10.9\%) \\
\hline & $16-20$ years & $24(8.4 \%)$ & $1(1.6 \%)$ \\
\hline & $21-25$ years & $22(7.7 \%)$ & $1(1.6 \%)$ \\
\hline & $26-30$ years & $15(5.2 \%)$ & $3(4.7 \%)$ \\
\hline & $31-35$ years & $10(3.5 \%)$ & $1(1.6 \%)$ \\
\hline & $36-40$ years & $14(4.9 \%)$ & $0(0 \%)$ \\
\hline & $41-45$ years & $8(2.8 \%)$ & $1(1.6 \%)$ \\
\hline & $46-50$ years & $5(1.7 \%)$ & $1(1.6 \%)$ \\
\hline & Over 50 years & $1(0.3 \%)$ & $2(3.1 \%)$ \\
\hline \multirow[t]{4}{*}{ Length of Ownership of Dog } & $<1$ year & $23(8 \%)$ & - \\
\hline & $1-5$ years & $153(53.5 \%)$ & - \\
\hline & $6-10$ years & 79 (27.6\%) & - \\
\hline & Over 10 years & 31 (10.8\%) & - \\
\hline \multirow[t]{4}{*}{ Dog Sex } & Male, entire & $32(11.2 \%)$ & - \\
\hline & Male, neutered & 107 (37.4\%) & - \\
\hline & Female, entire & $25(8.7 \%)$ & - \\
\hline & Female, neutered & $122(42.7 \%)$ & - \\
\hline
\end{tabular}

ESDS adapted for use with dogs will henceforth be referred to as Emotional Self Disclosure Scale-Dog Owners (ESDS-DO).

\section{Procedure}

The survey comprised of a consent page, a brief demographic questionnaire (Table 1), the ESDO-DO (for dog owners), or the ESDS (Snell et al., 1988; with the same textual adaptation but for non-dog owners). The survey was advertised through the use of social media, posters displayed in dog-groomers, boarding kennels, and general social clubs, along with a general media press release issued by the University of Lincoln press office. 
Table 2. Alpha-coefficients $(\alpha)$ for the eight scale factors on the Emotional Self Disclosure Scale-Dog Owners (ESDS-DO) and the Emotional Self Disclosure Scale (ESDS), for non-dog owners.

\begin{tabular}{lccccccc}
\hline & \multicolumn{3}{c}{ Dog Owners } & & \multicolumn{2}{c}{ Non-dog Owners } \\
\cline { 2 - 4 } & Partner & Confidant & Dog & & & Partner & Confidant \\
\cline { 2 - 4 } \cline { 7 - 8 } & $\alpha$ & $\alpha$ & & & $\alpha$ & $\alpha$ \\
\hline Factor 1: Depression & 0.905 & 0.896 & 0.954 & & 0.899 & 0.887 \\
Factor 2: Happiness & 0.928 & 0.940 & 0.958 & & 0.947 & 0.837 \\
Factor 3: Jealousy & 0.895 & 0.878 & 0.953 & & 0.909 & 0.879 \\
Factor 4: Anxiety & 0.905 & 0.906 & 0.959 & & & 0.896 & 0.890 \\
Factor 5: Anger & 0.896 & 0.889 & 0.962 & & & 0.916 & 0.915 \\
Factor 6: Calmness & 0.905 & 0.894 & 0.951 & & & 0.914 & 0.858 \\
Factor 7: Apathy & 0.899 & 0.887 & 0.958 & & 0.904 & 0.910 \\
Factor 8: Fear & 0.948 & 0.939 & 0.963 & & 0.952 & 0.949 \\
\hline
\end{tabular}

$\alpha>0.70=$ "good."

With the aim of informing potential participants about the nature of the topic without biasing the recruitment, the advertisements requested individuals to respond to a survey exploring "who we prefer to talk to," avoiding use of the term "emotional-disclosures." Respondents were asked to acknowledge that their participation in the survey was voluntary and confirm their eligibility (i.e., that they were over 18 years of age and had been in a relationship with the same partner and had owned the same dog - if they were a dog owner - each for at least six months). The survey was piloted before being hosted on Survey Monkey. Data collected between April and June 2015 were used in the analysis. All analyses were undertaken using SPSS 21 (Armonk, NY, USA). Bonferroni corrections were applied in the case of multiple comparisons.

\section{Results}

\section{Participant Characteristics}

In both the dog-owning sample and the non-dog owning sample there were more females than males. In both groups, individuals who resided in a European country, were aged 26-35 years, and had been in a relationship with their partner for $1-10$ years (collapsed across the categories 1-5 years and 6-10 years) were most represented.

\section{Internal Reliability}

To assess whether the scale construct of the ESDS and ESDS-DO remained consistent after changing "discuss" to "talk to" and including "dog" as a recipient, we computed Cronbach's alphas (Cronbach, 1951) for responses on each of the scales. For both dog owners (ESDSDO) and non-dog owners (ESDS) alpha coefficients exceeded the internal reliability criterion of $a>0.70=$ "good" (Table 2), and values relating to humans were similar to those reported for the original scale (Snell et al., 1988).

\section{Disclosure Patterns}

To assess whether there was a significant difference in willingness to talk to a pet dog (among dog owners), partner, or confidant for each of the eight emotional-disclosure topics, Analysis 


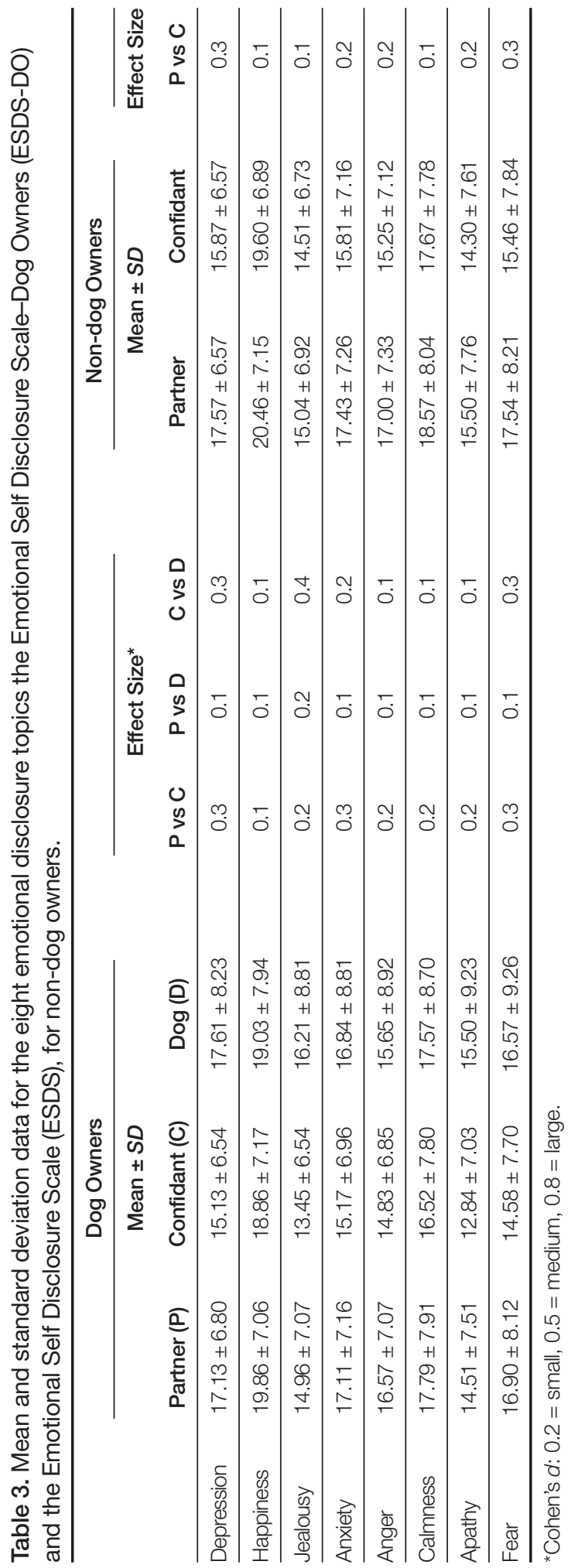


of Variance (ANOVA) was used for each of the groups. Table 3 reports descriptive statistics and Cohen's d effect sizes, whereby $0.2=$ small, $0.5=$ medium, and 0.8 = large (Cohen, 1969).

Depression: Dog owners showed significantly different patterns with regards to willingness to disclose depression across recipients (dog, partner, confidant) $\left(F_{(2,570)}=25.79, p<0.001\right)$. They were significantly more willing to talk to their partner and their dog than a confidant about this emotion $(p<0.001)$; there was no significant difference between willingness to talk to their partner and dog $(p>0.05)$. Non-dog owners were significantly more willing to talk to their partner than a confidant $\left(F_{(1,63)}=6.89, p<0.02\right)$.

Happiness: Dog owners demonstrated significantly different willingness to disclose on topics relating to happiness across recipients $\left(F_{(2,570)}=7.83, p<0.001\right)$. Dog owners were more willing to talk to their partners than their dog $(p<0.02)$ or a confidant on this topic $(p<0.001)$; there was no significant difference between willingness to talk to dog or confidant $(p>0.05)$. Likewise, non-dog owners were significantly more willing to talk to their partner than a confidant $\left(F_{(1,63)}=3.85, p=0.05\right)$.

Jealousy: On topics of jealousy, dog owners showed different willingness to disclose depending upon the recipient $\left(F_{(2,570)}=26.88, p<0.001\right)$. Dog owners were significantly more willing to talk to their dog than their partner $(p<0.02)$ and their confidant $(p<0.001)$ on topics of jealousy, and more willing to talk to their partner than their confidant on this topic $(p<0.001)$. Non-dog owners showed no significant difference in willingness to disclose on topics of jealousy between their partner and their confidant $\left(F_{(1,63)}=0.57, p>0.05\right)$.

Anxiety: Dog owners showed significantly different willingness to disclose on topics of anxiety depending upon the topic $\left(F_{(2,570)}=15.22, p<0.001\right)$. In comparison to a confidant, dog owners were more willing to talk to their partner $(p<0.001)$ and their dog $(p<0.001)$ on this topic. Non-dog owners were significantly more willing to talk to their partner than a confidant $\left(F_{(1,63)}=6.76, p<0.02\right)$.

Anger: On topics of anger, dog owners demonstrated significantly different willingness to disclose across recipients $\left(F_{(2,570)}=9.83, p<0.001\right)$. Dog owners were more willing to talk to their partner than their confidant $(p<0.001)$; there was no significant difference between partner and dog, or dog and confidant (ps $>0.05)$. Non-dog owners were significantly more willing to talk to their partner than their confidant $\left(F_{(1,63)}=7.28, p<0.01\right)$.

Calmness: Dog owners displayed different willingness to disclose on topics of calmness across different recipients $\left(F_{(2,570)}=11.29, p<0.001\right)$. Dog owners were more willing to talk to their partner $(p<0.001)$ and their dog $(p<0.01)$ than their confidant. There was no significant difference between willingness to talk to partner and dog on this emotion $(p>0.05)$. There was no significant difference between willingness to talk to partner or confidant for non-dog owners $\left(F_{(1,63)}=3.01, p>0.05\right)$.

Apathy: Dog owners were significantly more willing to disclose on topics of apathy to some recipients than others $\left(F_{(2,570)}=26.48, p<0.001\right)$. Dog owners were more willing to talk to their dog, compared with their partner $(p<0.05)$ and confidant $(p<0.001)$ on this topic. They were also more willing to talk to their partner compared with their confidant $(p<0.001)$. Non-dog owners were significantly more willing to talk to their partner than their confidant $\left(F_{(1,63)}=3.82, p=0.05\right)$. 


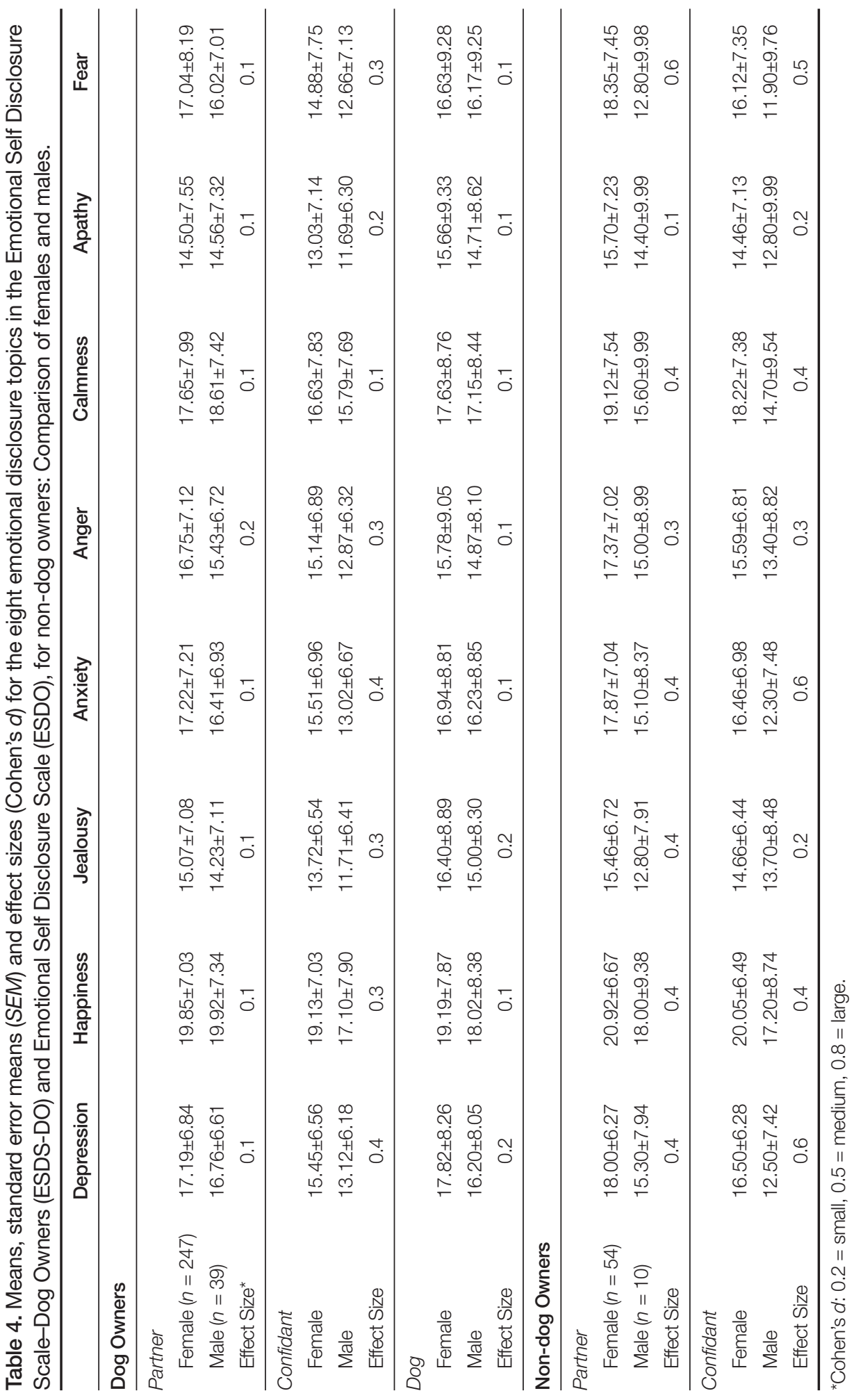


Fear: Dog owners demonstrated significantly different willingness to disclose on topics of fear across different recipients $\left(F_{(2,570)}=21.20, p<0.001\right)$. Dog owners were more willing to talk to their partner $(p<0.001)$ and their dog $(p<0.001)$, compared with their confidant. There was no significant difference between willingness to talk to partner and dog $(p>0.05)$. Non-dog owners were significantly more willing to talk to their partner than their confidant $\left(F_{(1,63)}=8.45, p<0.01\right)$.

\section{Factors Affecting Disclosure Patterns}

Given that this study represents one of the first explorations into willingness to disclose emotional topics to pet dogs, we were interested to explore differences in willingness to talk to recipients as a factor of age, sex (of participant and dog), and relationship length (with partner and with dog). ANOVAs were computed separately for the dog-owning and non-dog owning groups (the latter having no data for the variables relating to sex of the dog and length of relationship with the dog). Descriptive statistics and effect sizes are reported in Table 4. There was no significant difference in participants' willingness to disclose to their partner, confidant or dog (for the dog owning group) as a factor of their age, relationship length (including relationship length with the dog for the dog owning group), and the sex of their dog (for the dog-owning group) (all ps > 0.05). However, for the dog-owning group only, there was a significant effect of participant sex on willingness to disclose to their confidant on topics relating to depression $\left(F_{(1,96)}=4.52, p<0.02\right)$, anxiety, $\left(F_{(1,96)}=5.49, p<0.05\right)$, anger, $(F .=5.25$, $p<0.03)$, and jealousy $\left(F_{(1,96)}=4.29, p<0.05\right)$. For these topics, females were more willing than males to talk to their confidants. There were no significant differences in male and females dog owners' willingness to talk to their partner or their dog across the topics (all ps > 0.05). There was no statistically significant difference in non-dog owners' willingness to disclose to their partner or confidant across the topics ( $p>0.05)$, despite effect sizes for depression and fear approaching "medium," this may be a reflection of the comparably smaller sample size of this group.

Having identified that dog owners report a greater willingness to talk to their dog compared with their partner or a confidant about certain topics (jealousy and apathy) and that female dog owners report greater willingness to disclose about certain topics (jealousy, depression, anxiety and anger) to their confidants than male dog owners, we were motivated to explore whether willingness to talk about emotional topics to one's partner and confidant was affected by dog ownership status (dog owner vs non-dog owner) whilst controlling for demographic factors. To do this, analysis of covariance (ANCOVA) was used, with sex, agegroup, country, and relationship length (with partner) as co-variates. There was no significant difference between dog owners' and non-dog owners' willingness to talk to their partner or their confidant across the eight emotional topics in question (all ps > 0.05).

\section{Discussion}

The results from this study suggest that dogs play a similar role to a partner when it comes to emotional disclosures. Dog owners reported greater willingness to talk to their dog (and partner) compared with a confidant across the emotional disclosure topics of depression, jealousy, anxiety, calmness, apathy, and fear. For topics relating to jealousy and apathy, dog owners showed greater willingness to talk to their dog than their partner and confidant. However, between-group comparisons (dog owners vs non-dog owners) revealed that there was no significant difference in willingness to disclose to partners or confidants between dog owners 
and non-dog owners. This suggests that whilst dog owners may be more willing to talk to their dog about certain emotions, this does not impact upon their willingness to talk to other close confidants.

This is the first study, known to the authors, which identifies which emotional topics (jealousy and apathy) dog owners are more willing to talk to their dog about than a partner or a confidant. Feelings of jealousy are related to feelings of depression, anxiety, anger, selfesteem, suicide, and marital problems (Leary, 1990; Longmore, Manning, Giordano, \& Copp, 2014; Pines \& Aronson, 1983). Similarly, feelings of apathy have been related to mental health, including loss of motivation, cognitive dysfunction, and depression (Marin, 1991; Marin, Firinciogullari, \& Biedrzycki, 1993; Niino et al., 2014). Given the proposed health benefits of disclosure (Kane, Slatcher, Reynolds, Repetti, \& Robles, 2014; Koing, Eonta, Dyal, \& Vrana, 2014; Richardson \& Rice, 2015; Schrodt \& Afifi, 2016), this represents a potentially important finding in relation to mental health and guidance counselling.

It is interesting to note that dogs, in comparison with partners, perhaps provide a greater source of support for owners to talk to about negative emotions (jealousy and apathy) than happiness. Although we did not assess why dog owners may be more willing to talk about jealousy and apathy with their dogs than their partners, research suggests that owners often consider their pets as safe havens (Geisler, 2004; Kurdek, 2009), and act as a secure base, allowing them to explore and take risks more confidently (McNicholas \& Collis, 2000). Pets have also been shown to provide a source of comfort and support in times of need (Carr \& Rockett, 2017; Zilcha-Mano, Mikulincer, \& Shaver, 2011, 2012), over and above that experienced in the presence of a friend or family member (Allen et al., 1991, 2002). Thus, it might be that, they fulfil this function in the psychological world as well as the physical world. Future research employing qualitative research techniques could further uncover why owners may be more willing to talk to dogs about some topic areas, and uncover the psychological mechanisms involved.

For the majority of emotional-disclosure topics, dog owners displayed similar willingness to talk to their partner and their dog - both of whom were preferred recipients of disclosure than a confidant. This suggests that dogs are incorporated psychologically, at least in part, within family relationship networks, and may serve some similar roles as human family members (Bonas, McNicholas, \& Collis, 2000; Cohen, 2002). Although not included in this study, it may be particularly valuable to explore the impact of these effects of dog ownership amongst those without strong family or social networks who may be at higher risk of a range of mental health problems (Brown, Tracy, Jun, Park, \& Min, 2015; Perry \& Pescosolido, 2015; Sonnenberg et al., 2013).

There is little scientific exploration examining the longitudinal development of the emotional relationship between owners and dogs. Although the human literature suggests that disclosure develops with increased relationship length (Derlega, Winstead, \& Greene, 2007), we did not observe any effects on relationship length, with partner or dog, on disclosure preferences.

In contrast to other studies (Cassels et al., 2017; Kurdek, 2009), we did not observe significant differences between male and female dog owners' willingness to talk to their dog about the issues covered. However, the sample size was considerably smaller for males; this might reflect a general reduction in talking to dogs by males, but among those who do talk to their dogs, they seem as open as females in this regard. This suggests that other factors may interact to determine the sex differences reported, such as individual differences in personality, perceived support, or the specific nature of the topic in question. Future research should focus on identifying these possible mediating factors. 
Female dog owners and non-dog owners were more willing to talk to their confidant about negative emotions (depression, anxiety, jealousy, anger) than male dog owners. This is consistent with research highlighting sex differences in disclosure patterns and female willingness to talk to those whom they have a close non-romantic relationship with (Dindia \& Allen, 1992). However, this effect was not observed in the non-dog owning group. Whilst it could be suggested that dog ownership encourages females to open up to others, we did not observe any significant difference in willingness to talk to confidants when controlling for demographic factors (including participant sex). We suggest that future studies utilize the effect sizes reported here to conduct appropriately powered studies to compare the effect of sex on willingness to disclose between dog owner and non-dog owners.

Although this study makes an important contribution to our understanding of the humandog relationship and the role of disclosure, there are a number of limiting factors. In particular, the scale used in the study asks respondents about their "willingness" to talk to their dog, partner, or confidant, as opposed to assessing how frequently they talk to them. It is possible that what people say they would be willing to do and what they actually do are different. Having identified that the topic of emotional self-disclosure may be of importance to the field of humananimal interactions, it is suggested that future research uses more objective measures to assess willingness to talk to a pet, partner or confidant (such as assessments of frequency). However, given that disclosures may happen unconsciously (e.g., an individual absentmindedly talks to their pet about a topic whilst stroking them), it may be important to combine assessments of frequency and willingness. We also recognize that the design of the survey meant that non-dog owners had fewer items (i.e., a shorter survey) to complete than dog owners. Although we think it is unlikely to have affected the results, it is possible that dog owners experienced greater fatigue during the survey, which could have impacted upon their ability to accurately complete each item.

The study recruited considerably more female than male participants, which may have influence the observed results, and as such we reported effect sizes for male and females separately. Whilst we avoided use of the terms "emotional-disclosure" in the recruitment process, it was considered important that potential respondents were not deceived as to the nature of the topic under investigation. As such, it is possible that a study investigating "who we prefer to talk to" naturally appealed more to females than males. Future studies could consider targeted recruitment at male-orientated clubs (e.g., male dominated sports teams) in order to increase male participation.

Additionally, as previously mentioned, the survey approach makes it difficult to infer why dog owners may be more willing to talk to their dog about some topics of emotionaldisclosure. Having identified that significant differences exist in willingness to disclose to dogs, compared with partners and confidants, it is important that future research begins to explore the mechanisms involved in this effect. Furthermore, we did not assess how disclosure patterns may impact on psychological wellbeing. Based on the findings reported here, future research should specifically explore the link between disclosure topics in dog owners and depression, anxiety, self-esteem, and suicidal ideations. It would also be interesting to explore whether for individuals without romantic partners, pet dogs provide a greater source of support for disclosures, or whether close friends are then perceived as more favorable alternatives. Similarly, the strength of the attachment to a dog may affect willingness to disclose to it, since research suggests that attachment to a pet can impact upon the benefits of pet ownership (e.g., Hall et al., 2016; Krause-Parello \& Gulick, 2014). 
Although we recorded length of ownership, we did not include a pet attachment scale, and this may prove a useful addition to further work in this area.

This study reports an initial investigation into the role that pet dogs may provide as recipients of emotional disclosures, particularly those relating to jealousy and apathy. Given the importance of disclosing emotions on psychological health, it is vital that we continue to research how best to maximize the benefits of pet dog ownership to improve owner wellbeing and reduce associated costs on society and healthcare systems.

\section{Conflict of Interest}

The authors state that there is no conflict of interest.

\section{References}

Allen, K. (2003). Are pets a healthy pleasure? The influence of pets on blood pressure. Current Directions in Psychological Science, 12, 236-239.

Allen, K., Blascovich, J., \& Mendes, W. B. (2002). Cardiovascular reactivity and the presence of pets, friends, and spouses: The truth about cats and dogs. Psychosomatic Medicine, 64, 727-739.

Allen, K. M., Blascovich, J., Tomaka, J., \& Kelsey, R. M. (1991). Presence of human friends and pet dogs as moderators of autonomic responses to stress in women. Journal of Personality and Social Psychology, 61, 582-589.

Bonas, S., McNicholas, J., \& Collis, G. M. (2000). Pets in the network of family relationships: An empirical study. Companion animals and us: Exploring the relationships between people and pets (pp. 209-236). Cambridge: Cambridge University Press.

Brown, S., Tracy, E. M., Jun, M., Park, H., \& Min, M. O. (2015). Personal network recovery enablers and relapse risks for women with substance dependence. Qualitative Health Research, 25, 371-385.

Bryan, J. L., Quist, M. C., Young, C. M., Steers, M. L. N., Foster, D. W., \& Lu, Q. (2014). Canine comfort: Pet affinity buffers the negative impact of ambivalence over emotional expression on perceived social support. Personality and Individual Differences, 68, 23-27.

Carr, S., \& Rockett, B. (2017). Fostering secure attachment: Experiences of animal companions in the foster home. Attachment \& Human Development, 19, 259-277.

Cassels, M. T., White, N., Gee, N., \& Hughes, C. (2017). One of the family? Measuring early adolescents' relationships with pets and siblings. Journal of Applied Developmental Psychology, 49, 12-20.

Cirulli, F., Borgi, M., Berry, A., Francia, N., \& Alleva, E. (2011). Animal-assisted interventions as innovative tools for mental health. Annali dell'Istituto superiore di sanità, 47, 341-348.

Cohen, J. (1969). Statistical power analysis for the behavioral sciences. New York, NY: Academic Press.

Cohen, S. P. (2002). Can pets function as family members? Western Journal of Nursing Research, 24, 621638.

Cronbach, L. J. (1951). Coefficient alpha and the internal structure of tests. Psychometrika, 16, 297-334.

Derlega, V. J., \& Berg, J. H. (Eds.). (2013). Self-disclosure: Theory, Research, and Therapy. New York, NY: Springer.

Derlega, V. J., Winstead, B. A., \& Greene, K. (2008). Self-disclosure and starting a close relationship. In S. Sprecher, A. Wenzel, \& J. Harvey (Eds.), Handbook of relationship beginnings (pp. 153-174). New York, NY: Psychology Press.

Dindia, K., \& Allen, M. (1992). Sex differences in self-disclosure: A meta-analysis. Psychological Bulletin, 112, 106-124.

Forgas, J. P. (2011). Affective influences on self-disclosure: Mood effects on the intimacy and reciprocity of disclosing personal information. Journal of Personality and Social Psychology, 100, 449-461.

Geisler, A. M. (2004). Companion animals in palliative care: Stories from the bedside. American Journal of Hospice and Palliative Medicine, 21, 285-288.

Geist, T. S. (2011). Conceptual framework for animal assisted therapy. Child and Adolescent Social Work Journal, 28, 243-256.

Greene, K., Derlega, V. J., \& Mathews, A. (2006). Self-disclosure in personal relationships. The Cambridge Handbook of Personal Relationships (pp. 409-427). Cambridge: Cambridge University Press. 
Hall, S. S., Wright, H. F., Hames, A., PAWS Team, \& Mills, D. S. (2016). The long-term benefits of dog ownership in families with children with autism. Journal of Veterinary Behavior: Clinical Applications and Research, 13, 46-54.

Hollenbaugh, E. E., \& Ferris, A. L. (2014). Facebook self-disclosure: Examining the role of traits, social cohesion, and motives. Computers in Human Behavior, 30, 50-58.

Horne, R. M., \& Johnson, M. D. (2017). Gender role attitudes, relationship efficacy, and self-disclosure in intimate relationships. The Journal of Social Psychology, 1-14.

Kane, H. S., Slatcher, R. B., Reynolds, B. M., Repetti, R. L., \& Robles, T. F. (2014). Daily self-disclosure and sleep in couples. Health Psychology, 33, 813-822.

Knapp, M. L., Ellis, D. G., \& Williams, B. A. (1980). Perceptions of communication behavior associated with relationship terms. Communication Monographs, 47, 262-278.

Knight, S., \& Edwards, V. (2008). In the company of wolves the physical, social, and psychological benefits of dog ownership. Journal of Aging and Health, 20, 437-455.

Konig, A., Eonta, A., Dyal, S. R., \& Vrana, S. R. (2014). Enhancing the benefits of written emotional disclosure through response training. Behavior Therapy, 45, 344-357.

Krause-Parello, C. A., \& Gulick, E. (2014). Examining demographic and psychosocial predictors of well-being in older pet owners. International Journal of Nursing, 3, 29-42.

Kurdek, L. A. (2009). Pet dogs as attachment figures for adult owners. Journal of Family Psychology, 23, 439-446.

Leary, M. R. (1990). Responses to social exclusion: Social anxiety, jealousy, loneliness, depression, and low self-esteem. Journal of Social and Clinical Psychology, 9, 221-229.

Longmore, M. A., Manning, W. D., Giordano, P. C., \& Copp, J. E. (2014). Intimate partner victimization, poor relationship quality, and depressive symptoms during young adulthood. Social Science Research, 48, 77-89.

Ma, M. L., \& Leung, L. (2006). Unwillingness-to-communicate, perceptions of the Internet and self-disclosure in ICQ. Telematics and Informatics, 23, 22-37.

Marin, R. S. (1991). Apathy: A neuropsychiatric syndrome. The Journal of Neuropsychiatry and Clinical Neurosciences, 3, 243-254.

Marin, R. S., Firinciogullari, S., \& Biedrzycki, R. C. (1993). The sources of convergence between measures of apathy and depression. Journal of Affective Disorders, 28,117-124.

Matchock, R. L. (2015). Pet ownership and physical health. Current Opinion in Psychiatry, 28, 386-392.

McNicholas, J., \& Collis, G. M. (2000). Dogs as catalysts for social interactions: Robustness of the effect. British Journal of Psychology, 91, 61-70.

McNicholas, J., Gillbey, A., Rennie, A., Ahmedzai, S., Dono, J. A., \& Ormerod, E. (2005). Pet ownership and human health: A brief review of evidence and issues. BMJ, 331, 1252-1254.

Mills, D., \& Hall, S. (2014). Animal-assisted interventions: Making better use of the human-animal bond. Veterinary Record, 174, 269-273.

Niino, M., Mifune, N., Kohriyama, T., Mori, M., Ohashi, T., Kawachi, I., ... Kikuchi, S. (2014). Apathy/depression, but not subjective fatigue, is related with cognitive dysfunction in patients with multiple sclerosis. BMC Neurology, 14, 3-11. doi.org/10.1186/1471-2377-14-3.

O'Haire, M. (2010). Companion animals and human health: Benefits, challenges, and the road ahead. Journal of Veterinary Behavior: Clinical Applications and Research, 5, 226-234.

Perry, B. L., \& Pescosolido, B. A. (2015). Social network activation: The role of health discussion partners in recovery from mental illness. Social Science \& Medicine, 125, 116-128.

Pines, A., \& Aronson, E. (1983). Antecedents, correlates, and consequences of sexual jealousy. Journal of Personality, 51, 108-136.

Richardson, C. M., \& Rice, K. G. (2015). Self-critical perfectionism, daily stress, and disclosure of daily emotional events. Journal of Counseling Psychology, 62, 694-702.

Rogers, V. L., Griffin, M. Q., Wykle, M. L., \& Fitzpatrick, J. J. (2009). Internet versus face-to-face therapy: Emotional self-disclosure issues for young adults. Issues in Mental Health Nursing, 30, 596-602.

Schneider, M. S., \& Harley, L. P. (2006). How dogs influence the evaluation of psychotherapists. Anthrozoös, 19, 128-142.

Schrodt, P., \& Afifi, T. D. (2016). A social relations model of negative relational disclosures and closeness in families. Journal of Social and Personal Relationships. doi:10.1177/0265407516680304. 
Siegel, J. M. (1990). Stressful life events and use of physician services among the elderly: The moderating role of pet ownership. Journal of Personality and Social Psychology, 58, 1081-1086.

Sinha, V. (1972). Age differences in self-disclosure. Developmental Psychology, 7, 257-258.

Snell Jr, W. E., Miller, R. S., \& Belk, S. S. (1988). Development of the emotional self-disclosure scale. Sex Roles, 18, 59-73.

Sonnenberg, C. M., Deeg, D. J. H., Van Tilburg, T. G., Vink, D., Stek, M. L., \& Beekman, A. T. F. (2013). Gender differences in the relation between depression and social support in later life. International Psychogeriatrics, 25, 61-70.

Tokić, A., \& Pećnik, N. (2011). Parental behaviors related to adolescents' self-disclosure: Adolescents' views. Journal of Social and Personal Relationships, 28, 201-222.

Valkenburg, P. M., \& Peter, J. (2007). Preadolescents' and adolescents' online communication and their closeness to friends. Developmental Psychology, 43, 267-277.

Wright, H. F., Hall, S., Hames, A., Hardiman, J., Mills, R., Mills, D. S., \& PAWS Team. (2015). Acquiring a pet dog significantly reduces stress of primary carers for children with Autism Spectrum Disorder: A prospective case control study. Journal of Autism and Developmental Disorders, 45, 2531-2540.

Zilcha-Mano, S., Mikulincer, M., \& Shaver, P. R. (2011). An attachment perspective on human-pet relationships: Conceptualization and assessment of pet attachment orientations. Journal of Research in Personality, 45, 345-357.

Zilcha-Mano, S., Mikulincer, M., \& Shaver, P. R. (2012). Pets as safe havens and secure bases: The moderating role of pet attachment orientations. Journal of Research in Personality, 46, 571-580. 